NBER WORKING PAPER SERIES

\title{
LIMITED ASSET MARKET PARTICIPATION AND THE ELASTICITY OF INTERTEMPORAL SUBSTITUTION
}

\author{
Annette Vissing-Jorgensen \\ Working Paper 8896 \\ http://www.nber.org/papers/w8896 \\ NATIONAL BUREAU OF ECONOMIC RESEARCH \\ 1050 Massachusetts Avenue \\ Cambridge, MA 02138 \\ April 2002
}

This paper is a revised version of the first chapter of my MIT thesis. I thank my advisors Daron Acemoglu, Olivier Blanchard, and especially Ricardo Caballero for their insights and advice. Seminar and conference participants and discussants at MIT, Princeton, Rochester, Chicago, Northwestern, Kellogg, Stanford, NYU, Columbia, Wisconsin, UCL, Tilburg, Toulouse, Tel Aviv, Milan, the NBER Summer Institute, and the AEA Meetings provided very useful comments and suggestions. All errors are mine. Financial support from the Danish Research Academy, the Sloan Foundation, and the University of Chicago is greatfully acknowledged. The views expressed herein are those of the author and not necessarily those of the National Bureau of Economic Research.

(C) 2002 by Annette Vissing-Jorgensen. All rights reserved. Short sections of text, not to exceed two paragraphs, may be quoted without explicit permission provided that full credit, including $(\mathcal{C}$ notice, is given to the source. 
Limited Asset Market Participation and the Elasticity of Intertemporal Substitution Annette Vissing-Jorgensen

NBER Working Paper No. 8896

April 2002

JEL No. E2, G1

\begin{abstract}
The paper presents empirical evidence based on the US Consumer Expenditure Survey that accounting for limited asset market participation is important for estimating the elasticity of intertemporal substitution (EIS). Differences in estimates of the EIS between assetholders and non-assetholders are large and statistically significant. This is the case whether estimating the EIS based on the Euler equation for stock index returns or the Euler equation for T-bills, in each case distinguishing between assetholders and non-assetholders as best possible. Estimates of the EIS are around 0.3-0.4 for stockholders and around 0.8-1 for bondholders, and are larger for households with larger asset holdings within these two groups.
\end{abstract}

\author{
Annette Vissing-Jorgensen \\ Department of Economics \\ University of Chicago \\ 1126 E. 59th Street \\ Chicago, IL 60637 \\ and NBER
}

Tel: $773-702-9127$

Fax: $773-702-8490$

Email: vissing@uchicago.edu

Web: www.src.uchicago.edu/users/viss 


\section{Introduction}

The elasticity of intertemporal substitution is one of the central determinants of households' intertemporal consumption choices. In the certainty case it can be computed as minus the elasticity of the ratio of consumption in period $t$ to consumption in period $t+1$ with respect to the relative price of consumption in the two periods

$$
E I S=-\frac{d\left(C_{t} / C_{t+1}\right)}{d\left(1+R_{f, t}\right)} \frac{\left(1+R_{f, t}\right)}{C_{t} / C_{t+1}}=\frac{d\left(\ln \left(C_{t+1} / C_{t}\right)\right)}{d\left(\ln \left(1+R_{f, t}\right)\right)}
$$

where $R_{f, t}$ is the net return on the riskless asset in period $t$. Under uncertainty, one can define utility over consumption in this period and the certainty equivalent of future consumption following Epstein and Zin (1989). The elasticity of intertemporal substitution can then be defined based on the ratio of current period consumption to the certainty equivalent of future consumption. Assuming, firstly, that asset returns and next period consumption are joint log normally distributed conditional on information known in this period and, secondly, that utility is of the Epstein-Zin form or (as a special case) the constant relative risk aversion form, the elasticity of intertemporal substitution can be calculated as

$$
E I S=\frac{d E_{t}\left(\ln \left(C_{t+1} / C_{t}\right)\right)}{d E_{t}\left(\ln \left(1+R_{i, t}\right)\right)}
$$

where $R_{i, t}$ is the net return in period $t$ on any asset $i$ in which the consumer has an interior position. ${ }^{1}$ In other words, the EIS determines how much consumers change their expected consumption growth rate in response to changes in the expected return to any such asset.

Determining the sensitivity of consumption to interest rates is important for a host of economic issues and policies. For example, (a) the response of household savings to changes in after-tax interest rates depends crucially on the EIS, (b) the effect of expansionary fiscal policy is weaker if the EIS is large, and (c) the ability of real business cycle models to fit the data depends on the EIS (see e.g. Jones, Manuelli and Siu (2000) regarding (c)).

A quite large empirical literature has been devoted to estimating the EIS. Most work has focused on estimating it assuming constant relative risk aversion preferences and using the log-linearized Euler equation derived by Hansen and Singleton (1983). Hall (1988) summarized the evidence up to the late eighties by concluding that the EIS is unlikely to be much above 0.1 and may well be zero. While some subsequent studies, e.g. Attanasio and Weber (1993), have found positive and significant values of the EIS, it seems fair to say that there is no consensus on whether it is significantly above zero and

\footnotetext{
${ }^{1}$ See Attanasio and Weber (1989) for the derivation of the log-linearized Euler equation in the Epstein-Zin case.
} 
if so what its value is.

In this paper I use microdata from the U.S. Consumer Expenditure Survey (the CEX) to argue that accounting for limited asset market participation is crucial for obtaining consistent estimates of the EIS. The Euler equation should hold for a given household only if the household holds a non-zero position (positive or negative) in the asset. There is no theoretical reason for expecting households who do not hold a given asset to adjust its consumption growth rate in response to predictable changes in the return on that asset. In that case including the consumption of non-assetholders in Euler equation estimations will lead to inconsistent estimates of the EIS. In particular, if the consumption growth of non-assetholders does not comove with predictable asset return changes at all, then EIS estimates based on the consumption of all households will be substantially downward biased. ${ }^{2}$ To test this prediction I estimate log-linearized Euler equations involving T-bill returns as well as loglinearized Euler equations involving the return on the NYSE stock market index. In each case I distinguish, as best possible given the CEX data, between households who hold the asset in question and households who do not. I find estimates of the EIS around 0.3-0.4 for stockholders and around 0.8-1 for bondholders, with larger values for the third of households within these two groups who have the largest holdings of the asset. For non-stockholders and non-bondholders EIS estimates are small and insignificantly different from zero. Interestingly, in their paper in this volume Attanasio, Banks, and Tanner also find support for the limited asset market participation theory using data for the United Kingdom. These findings are consistent with earlier work by Attanasio and Browning (1995) showing that the elasticity of intertemporal substitution is increasing in consumption, given the large correlation of consumption and wealth and the fact that wealth is known to be a strong predictor of stock and bond market participation.

It is important to emphasize that the differences in EIS estimates between assetholders and nonassetholders should not be interpreted as evidence of heterogeneity in the EIS across households. Since the Euler equation for a given asset return cannot be expected to hold for households who do not hold a position in that asset, EIS estimates for non-assetholders are not consistent estimates of the EIS for these households. They are shown only to reconcile my findings of fairly large values of the EIS for assetholders with the finding of earlier studies. In fact it may be that the EIS is similar for assetholders and non-assetholders. In a recent paper, Gross and Souleles (2001) find a significant negative relation between the interest rate on credit cards and the amount of credit card borrowing, suggesting that

\footnotetext{
${ }^{2}$ For example, suppose households have constant relative risk aversion preferences and consumption growth rates and asset returns are conditionally joint log normal. If the consumption growth of non-assetholders does not covary with the instruments used to predict the asset return, it can be shown that EIS estimates based on estimation of conditional Euler equations using the consumption growth rates of all households is only factor $\lambda$ of the true value, where $\lambda$ is the fraction of assetholders in the population. The derivation of this is based on cross-sectional aggregation of individual Euler equations as in the empirical section below.
} 
the EIS is significantly positive for credit card borrowers as well. See also Attanasio, Goldberg and Kyriazidou (2000) for evidence that the demand for automobile loans is sensitive to the interest rate for most of the groups of households considered.

The idea that limited participation in asset markets matters for consumption and asset returns was originally proposed by Mankiw and Zeldes (1991). They estimated unconditional Euler equations for stockholders and non-stockholders using data from the Panel Study of Income Dynamics. Based on unconditional Euler equations, they found large differences in relative risk aversion estimates between the two groups although the estimate remained as high as 35 for the richest group of stockholders. Brav and Geczy (1996), and the extended version by Brav, Constantinides and Geczy (1999), confirm Mankiw and Zeldes' findings for unconditional Euler equations using CEX data. They show that risk aversion estimates are much larger for households who are likely to hold stocks and bonds than for others, and that risk aversion estimates decline as they look at still wealthier layers of assetholders. They estimate risk aversion to be 12 for the richest assetholders. I the present paper, I focus on the effects of limited participation for estimates of the elasticity of intertemporal substitution rather than estimates of risk aversion. Mankiw and Zeldes (1991) and Brav, Constantinides and Geczy (1999) do not provide standard errors for their estimates. However, bootstrap methods show that the standard errors of risk aversion estimates based on unconditional Euler equations are very large, especially when using a relatively short time period as is available from the Consumer Expenditure Survey (see Vissing-Jørgensen (1999)). This suggests that adding information about predictable movements in expected consumption growth rates and expected asset returns is valuable for improving the precision of the estimates. If, however, preferences are not of the CRRA form, the coefficient of relative risk aversion does not equal the inverse of the EIS. More specifically, in the case of Epstein-Zin preferences, estimation of conditional log-linearized Euler equations, with log consumption growth regressed on $\log$ asset returns, provides estimates of the EIS but is not informative about risk aversion, see e.g. Attanasio and Weber (1989). Therefore, while the findings of the present paper suggest that accounting

for limited asset market participation is crucial for obtaining reasonable values of the elasticity of intertemporal substitution, it is too early to precisely determine the extent to which it helps resolve the equity premium puzzle.

\section{Empirical results based on the Consumer Expenditure Survey}

\subsection{Data}

The available data from the Consumer Expenditure Survey cover the period 1980, first quarter to 1996, first quarter. In each quarter approximately 4500 households are interviewed. Each household is interviewed five times. The first time is practice and the results are not in the data files. The 
interviews are three months apart and when interviewed households are asked to report consumption for the previous three months. Financial information is gathered in the fifth quarter only. Aside from attrition, the sample is representative of the US population. Attrition is quite substantial with only about 60 percent of the households making it through all five interviews.

\subsubsection{Asset holder status}

The CEX contains information about four categories of financial assets. Households are asked for their holdings of "stocks, bonds, mutual funds and other such securities", "U.S. savings bonds", "savings accounts", and "checking accounts, brokerage accounts and other similar accounts".

I perform estimations firstly based on the return on the NYSE stock market index and then based on the return on Treasury bills. Thus, I would like to separate households into those who own stocks versus those who do not, as well as into those who hold bonds, T-bills or similar assets versus those who do not. As is clear from the above categories a perfect separation of households is not possible. In general, inability to perfectly identify assetholders from non-assetholders biases against finding differences in EIS estimates for the two groups. I will refer to households with positive responses to the category "stock, bonds, mutual funds and other such securities" as stockholders and focus on this distinction when estimating Euler equations for the stock index return. As for bondholdings, I will refer to households with positive responses to the stock, bonds and mutual funds category or to the U.S. savings bond category as bondholders (thus my sets of stockholders and bondholders differ by the group of households who own U.S. savings bonds). Again, not all of those with positive holdings of stocks, bonds or mutual funds necessarily hold bonds or bond mutual funds but many likely do. I do not include households with positive holdings in savings accounts in the bondholder category but return to these households after the main estimation results.

The Euler equation involving consumption in period $t$ and $t+1$ should hold for those who hold the asset as of date $t$. Therefore asset holding status must be defined based on stockholdings at the beginning of period $t$ (when considering the consumption growth between period $t$ and $t+1$ ). Two additional CEX variables are used for this purpose. The first one reports whether the household holds the same amount, more, or less of the asset category compared to a year ago. The second one reports the dollar difference in the estimated market value of the asset category held by the household last month compared with the value of the asset category held a year ago last month. I define a household as holding an asset category at the beginning of period $t$ if it 1) reports holding the same amount of the asset as a year ago and holds a positive amount at the time of the interview (the fifth interview) or 2) reports having lower holdings of the asset than a year ago, or 3) reports having had an increase in its holdings of the asset but by a dollar amount less than the reported holdings at the time of the 
question. ${ }^{3}$ Based on this I classify 21.75 percent of households as stockholders and 31.40 percent as bondholders.

It is known from e.g. the Survey of Consumer Finances that many households hold stocks or bonds only in their pension plan. Whether these should be considered stockholders/bondholders or not depends on the type of pension plan. In a defined contribution pension plan households can (within some limits) adjust their contributions and allocations and thus ensure that the Euler equation for the asset return is satisfied. Unfortunately, it is not possible to determine whether households with defined contribution plans report their stockholdings and bondholdings in these plans when answering the CEX questions. The percent of stockholders in the CEX is smaller than in other sources. ${ }^{4}$ This may indicate that some households with stockholdings in defined contribution plans do not report these. This will lead them to be miscategorized as non-stockholders, a problem which may also occur for bondholdings. Again, this should bias against finding differences between assetholders and nonassetholders.

In addition to the split between stockholders and non-stockholders, and the split between bondholders and non-bondholders, the set of stockholders and the set of bondholders is split into three layers of approximately equal size based on dollar amounts reported. Consistent with the definition of asset holding status this was done based on initial holdings. These were calculated as current holdings minus the change in holdings during the current period. Transactions costs may be less important for wealthier households, making it more likely that their Euler equations for stocks and bonds hold. Furthermore, wealthier households typically hold better diversified equity portfolios. The return on their equity portfolio is thus closer to the stock market index return used here. The bottom layer of stockholders consists of those reporting initial stockholdings of $\$ 2-\$ 3487$ in real 1982-1984 dollars, using the CPI to for total consumption of urban households to deflate the nominal values. The middle and top layers are those with real initial stockholdings of $\$ 3487-\$ 20264$ and above $\$ 20264$, respectively. For interviews conducted from 1991 onwards, about 5 percent of households report holdings of stocks, bonds and mutual funds of $\$ 1$. I contacted the BLS to determine if this was a coding error, but they were not sure how to interpret the $\$ 1$ answers. Since all of the households reporting $\$ 1$ assetholdings answer the question comparing current holdings to holdings a year ago it is likely that they are holding

\footnotetext{
${ }^{3}$ Around 600 households in my final sample of 34310 households report an increase in their holdings of stocks, bonds and mutual funds but do not report their current holdings. Most of these households are likely to have held these assets a year ago and I therefore put them in the stockholder category. Similarly around 400 households report an increase in their holdings of U.S. savings bonds but do not report their current holdings. I classify these as bondholders.

A small number of households report an increase in their holdings of stocks, bonds or mutual funds or of U.S. savings bonds larger than the value of the reported end of period holdings. I classify these as non-assetholders.

${ }^{4}$ This is the case whether using the CEX weights or not. Consistent with data from other sources, the proportion of stockholders is upward trending during the sample.
} 
such assets. I therefore include them as stockholders when doing the stockholder-nonstockholder classification (assuming they satisfy the criteria outlined above). However, since the $\$ 1$ households cannot be classified by layer of stockholding, I exclude them in estimations based on layers of stockholders. Thus the total number of stockholders used when defining layers is smaller than the total amount of stockholders when not doing this split. As for the three layers of bondholders, these were calculated based on the sum of the holdings of stock, bonds, and mutual funds, and U.S. savings bonds, again excluding households reporting $\$ 1$ holdings of the first category. The least wealthy third had holdings below $\$ 967$, while the middle third had holding between $\$ 967$ and $\$ 9881$, and the top third held more than $\$ 9881$ combined in these the asset categories.

\subsubsection{Consumption measure and sample choice}

The consumption measure used is nondurables and some services aggregated as carefully as possible from the disaggregate CEX consumption categories to match the definitions of nondurables and services in the NIPA. The service categories excluded are housing expenses (but not costs of household operations), medical care costs, and education costs. This is done since these three types of costs have a substantial durable component. Attanasio and Weber (1995) use a similar definition of consumption. In leaving out durables, it is implicitly assumed that utility is separable in durables and nondurables/services. Nominal consumption values are deflated by the BLS deflator for nondurables for urban households.

As discussed in more detail below I use semiannual consumption growth rates, defined as $\frac{C_{m+6}+C_{m+7}+C_{m+8}+C_{m+9}+C_{m+10}+C_{m+11}}{C_{m}+C_{m+1}+C_{m+2}+C_{m+3}+C_{m+4}+C_{m+5}}$ where $m$ refers to month $m$. Following Zeldes (1989) extreme outliers are dropped under the assumption that these reflect reporting or coding errors. Specifically, I drop observations for which the consumption growth ratio stated is less than 0.2 or above 5 (35 observations). Results are similar if I keep these observations. In addition, non-urban households (missing for part of the sample) and households residing in student housing are dropped as are households with incomplete income responses. Furthermore, I drop households who report a change in age of household head between any two interviews different from 0 or 1 year. These exclusions are standard. More drastically, I drop all consumption observations for households interviewed in 1980 and 1981, since the quality of the CEX consumption data is lower for this period. For example, Figure A.1 in Parker (1999) shows that the ratio of food consumption to income in the CEX is substantially higher before 1982 and that a similar pattern is not present in the Panel Study of Income Dynamics or the National Income and Product Accounts. Attanasio and Weber (1995) show that the share of food in nondurable consumption was much higher in 1980 and 1981 than subsequently.

Finally, because the financial information is reported in interview five, and because I wish to calculate consumption growth values by household, households must be matched across quarters. Therefore, 
I drop households for which any of interviews two to five are missing. Matching households across interviews creates problems around the beginning of 1986 since sample design and household identification numbers were changed, with no records being kept of which new household identification numbers correspond to which old ones. I therefore exclude households who did not finish their interviews before the ID change. This implies that no observations are available for 7 months around the ID change. This is taken into account when programming corrections for autocorrelation. The final sample consists of 34310 semiannual consumption growth observations.

Table 1 gives the average number of observations per month for the various household groups, along with the mean and standard deviation of their semiannual average log consumption growth (not annualized). The average number of observations for stockholders per month is 47 , while the average number of observations for non-stockholders is 170 . There are on average 68 bondholders and 148 nonbondholders per month. Data are also shown for a restricted sample consisting of single individual households only. This sample has substantially fewer observations. Therefore it is not possible to consider layers of stockholders and bondholders in this case. The summary statistics on consumption in Table 1 show that log consumption growth is higher for stockholders and bondholders than for non-stockholders and non-bondholders.

\subsubsection{Asset returns and other data used}

Monthly NYSE value weighted returns are used as the stock return measure and monthly T-bill returns as the measure of nominally riskless returns. The CPI for total consumption of urban households is used to calculate real returns. Semiannual returns are aggregated up from the real monthly returns. As instruments for the log stock return and the log T-bill return I use the log dividend price ratio, the lagged log real value weighted NYSE return, the lagged log real T-bill return, the government bond horizon premium, and the corporate bond default premium (in addition to seasonal dummies and family size controls). The choice of instruments is discussed further below. The dividend price ratio, the bond horizon premium and the bond default premium are based on data from Ibbotson (1997). The dividend price ratio used is the ratio of dividends over the previous 12 months to the

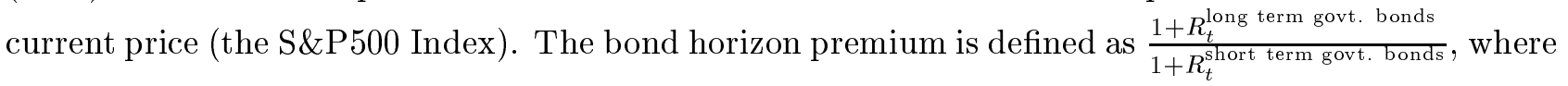
'long term' means 20 years to maturity and 'short term' means approximately 1 month to maturity.

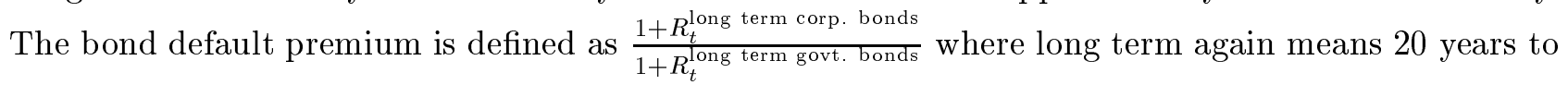
maturity. The monthly values for the bond horizon and default premia are aggregated multiplicatively to semiannual values. 


\subsection{Econometric issues}

\subsubsection{Timing}

The fact that households are interviewed every three months for a year, and in each interview report consumption for the previous quarter leaves open a choice of data frequency for defining consumption growth rates. I use semiannual consumption growth rates as defined above, and thus have one consumption growth observation per household interviewed. The first motivation for using semiannual rather than quarterly consumption growth rates, is that households may not reoptimize and optimally adjust their consumption every quarter (or even if so, may not do it close to the interview dates). In the context of risk aversion estimation, Lynch (1996), Daniel and Marshall (1997) and Gabaix and Laibson (2001) discuss how this leads to a downward biased prediction for the equity premium, and thus by implication an upward biased risk aversion estimate, when individual consumption is aggregated across households. Using consumption observations further apart, on average 6 months for semiannual consumption growth rates, alleviates the problem. A second argument in favor of longer time horizons is measurement error. If measurement errors have an additive component, this will tend to cancel over longer periods. Furthermore, measurement errors may be negatively correlated with the true consumption value. Daniel and Marshall (1997) suggest that measurement errors that are negatively correlated with the true value can occur if consumption innovations are only gradually incorporated into reported consumption over time. This will bias the covariance of consumption growth rates and asset returns downward, but less so if the consumption observations are further apart. Consistent with the concerns given, in my exercise results based on quarterly data were much weaker than those based on semiannual data. Results based on the change from first interview quarterly consumption to last interview quarterly consumption were quite similar to those based on semiannual consumption growth rates.

Using semiannual consumption growth rates raises the issue of precisely which asset return to use. For semiannual data, is the relevant asset return $\left(1+R_{m}\right)\left(1+R_{m+1}\right) \ldots\left(1+R_{m+5}\right)$ or $\left(1+R_{m+6}\right)$ $\left(1+R_{m+7}\right) \ldots\left(1+R_{m+11}\right)$ or something in between? Suppose consumers sell their assets (stocks or bonds) at the beginning of the month in which they would like to consume. Then shifting consumption from period $m$ to $m+6$ would imply a gross return of $\left(1+R_{m}\right)\left(1+R_{m+1}\right) \ldots . .\left(1+R_{m+5}\right)$, whereas shifting consumption from period $m+5$ to $m+11$ would yield a return of $\left(1+R_{m+5}\right)\left(1+R_{m+6}\right) \ldots$ $\left(1+R_{m+10}\right)$. Thus the relevant asset return would be a weighted average of all of $\left(1+R_{m}\right),\left(1+R_{m+1}\right), \ldots,\left(1+R_{m+10}\right)$. For simplicity I use the middle six months of relevant interest rates $\left(1+R_{m+2}\right)\left(1+R_{m+3}\right) \ldots\left(1+R_{m+7}\right)$. Results were similar when using $\left(1+R_{m+3}\right)\left(1+R_{m+4}\right) \ldots$ $\left(1+R_{m+8}\right)$.

While each household is interviewed three months apart, the interviews are spread out over the 
quarter implying that there will be households interviewed in each month of the sample. Thus the data frequency is monthly. This implies that consumption growth observations for adjacent months will involve partially overlapping time periods and thus partially overlapping expectational errors. As a consequence the error term in the log-linearized model will have an MA(5) component when using semiannual consumption growth observations.

Autocorrelation raises the question of which lags of interest rates and other variables are valid instruments. The error term has an expectational error component and a measurement error component. Since asset returns and other aggregate financial variables are likely to be uncorrelated with the measurement error component of the error term, autocorrelation due to measurement error does not invalidate lags of asset returns or other aggregate financial variables as instruments. The autocorrelation in the error term due to overlapping expectational errors imply that asset return lags six and further back are valid instruments. Due to the fact that $R_{m}$ and $R_{m+1}$ may be partly relevant as right hand side variables as discussed above, the asset return instruments used are lagged further so that there is no overlap. Thus $\left(1+R_{m-6}\right)\left(1+R_{m-5}\right) \ldots . .\left(1+R_{m-1}\right)$ is used as instrument. As for the specific asset returns used, I will return to when stock returns and T-bills returns are used when discussing the results. Similar considerations lead to using the dividend price ratio at the beginning of period $m$ as an instrument, as well as the bond horizon premium and bond default premium over the period $m-6$ to $m-1$.

\subsubsection{Measurement error}

The conditions on measurement error under which consistent estimates of the EIS can be obtained based on estimation of Euler equations are quite strict. The measurement error in individual consumption must be multiplicative and independent of the true consumption level and asset returns. This is the case whether the Euler equations are log-linearized or not. For simplicity the argument below therefore uses the nonlinear Euler equations.

To be specific, suppose first that we have a long time series of consumption observations for an agent $\mathrm{h}$ and wish to test the CCAPM. Let $C_{t}^{h, *}$ be the true consumption of household h in period $t$ and assume observed consumption is given by $C_{t}^{h}=C_{t}^{h, *} \varepsilon_{t}^{h}$, where $\varepsilon_{t}^{h}$ is the measurement error. Under CRRA utility with risk aversion parameter $\gamma(=1 / E I S)$, the true Euler equation for household $h$ and asset $i$ is

$$
E_{t}\left[\beta\left(\frac{C_{t+1}^{h, *}}{C_{t}^{h, *}}\right)^{-\gamma}\left(1+R_{i, t}\right)\right]=1
$$


However, our estimates $\hat{\beta}$ and $\hat{\gamma}$ will be based on sample equivalents of

$$
E_{t}\left[\beta\left(\frac{C_{t+1}^{h}}{C_{t}^{h}}\right)^{-\gamma}\left(1+R_{i, t}\right)\right]=1 \Leftrightarrow E_{t}\left[\beta\left(\frac{C_{t+1}^{h, *} \varepsilon_{t+1}^{h}}{C_{t}^{h, *} \varepsilon_{t}^{h}}\right)^{-\gamma}\left(1+R_{i, t}\right)\right]=1
$$

As an example, in the case of GMM estimation with two asset returns and two instruments, one of which is a column of ones, the estimates $\hat{\beta}$ and $\hat{\gamma}$ satisfy the sample equivalents of the above equation with equality. If $\varepsilon_{t+1}^{h}$ and $\varepsilon_{t}^{h}$ are conditionally independent of $C_{t+1}^{h}, C_{t}^{h}$, and $R_{i, t}$ (and the non-trivial instrument used), (4) implies

$$
E_{t}\left[\left(\frac{\varepsilon_{t+1}^{h}}{\varepsilon_{t}^{h}}\right)^{-\gamma}\right] E_{t}\left[\beta\left(\frac{C_{t+1}^{h, *}}{C_{t}^{h, *}}\right)^{-\gamma}\left(1+R_{i, t}\right)\right]=1
$$

If $E_{t}\left[\left(\frac{\varepsilon_{t+1}^{h}}{\varepsilon_{t}^{h}}\right)^{-\gamma}\right]$ is constant over time as would be the case with i.i.d. measurement errors, it follows that the estimator of $\beta$ will be inconsistent by this factor, whereas $\gamma$ will be consistently estimated. If measurement errors are i.i.d. lognormal, $\ln \varepsilon_{t}^{h} \sim N\left(\mu_{\varepsilon}, \sigma_{\varepsilon}^{2}\right) \forall t, \beta$ will be inconsistent by the factor $E_{t}\left[\left(\frac{\varepsilon_{t+1}^{h}}{\varepsilon_{t}^{h}}\right)^{-\gamma}\right]=\exp \left(\gamma^{2} \sigma_{\varepsilon}^{2}\right) .^{5}$

If we do not have a long time series of consumption for each agent and instead average marginal rates of substitution over consumers within each period, it can be shown that as the number of households in the cross-section at each date goes to infinity, $\gamma$ is still consistently estimated and the inconsistency in $\beta$ is as given above. To see this, suppose that at least two observations are available for each household such that $C_{t+1}^{h} / C_{t}^{h}$ can be calculated. When aggregating the marginal rates of substitution cross-sectionally, using a time series of cross-sections of $C_{t+1}^{h} / C_{t}^{h}$ observations, $\widehat{\beta}$ and $\widehat{\gamma}$ will be based on the sample equivalents of

$$
E_{t}\left[\beta \frac{1}{H} \Sigma_{h}\left[\left(\frac{C_{t+1}^{h}}{C_{t}^{h}}\right)^{-\gamma}\right]\left(1+R_{i, t}\right)\right]=1 \Leftrightarrow E_{t}\left[\beta \frac{1}{H} \Sigma_{h}\left[\left(\frac{C_{t+1}^{h, *} \varepsilon_{t+1}^{h}}{C_{t}^{h, *} \varepsilon_{t}^{h}}\right)^{-\gamma}\right]\left(1+R_{i, t}\right)\right]=1 .
$$

or as $H \rightarrow \infty$

$$
E_{t}\left[\beta E_{h}\left[\left(\frac{C_{t+1}^{h}}{C_{t}^{h}}\right)^{-\gamma}\right]\left(1+R_{i, t}\right)\right]=1 \Leftrightarrow E_{t}\left[\beta E_{h}\left[\left(\frac{C_{t+1}^{h, *} \varepsilon_{t+1}^{h}}{C_{t}^{h, *} \varepsilon_{t}^{h}}\right)^{-\gamma}\right]\left(1+R_{i, t}\right)\right]=1 .
$$

Under the independence assumptions stated above between measurement errors, true consumption

\footnotetext{
${ }^{5}$ Similarly, $\widehat{\ln \beta}$ in the log-linearized model will be inconsistent by the quantity $\gamma^{2} \sigma_{\varepsilon}^{2}$. However, since the intercept in the log-linearized model includes higher order moments it is not possible to accurately estimate $\beta$ from this intercept even in the absense of measurement error.
} 
and asset returns, and assuming i.i.d. log normal measurement errors across households, this implies

$$
\begin{gathered}
E_{t}\left[\beta E_{h}\left[\left(\frac{C_{t+1}^{h, *}}{C_{t}^{h, *}}\right)^{-\gamma}\right] E_{h}\left[\left(\frac{\varepsilon_{t+1}^{h}}{\varepsilon_{t}^{h}}\right)^{-\gamma}\right]\left(1+R_{i, t}\right)\right]=1 \Leftrightarrow \\
\exp \left(\gamma^{2} \sigma_{\varepsilon}^{2}\right) E_{t}\left[\beta E_{h}\left[\left(\frac{C_{t+1}^{h, *}}{C_{t}^{h, *}}\right)^{-\gamma}\right]\left(1+R_{i, t}\right)\right]=1 .
\end{gathered}
$$

Thus as $H \rightarrow \infty$ (and $T \rightarrow \infty), \widehat{\gamma}$ will again be consistent and $\beta$ will be inconsistent by the same factor as above. Since this argument for consistency of $\widehat{\gamma}$ even in the presence of measurement error relies on $H \rightarrow \infty$ and the number of observations in the cross-section is small in some of the cases considered, I will also consider a 'median household approach' which is likely to be more robust to small numbers of households in the cross-sections. ${ }^{6}$

\subsubsection{Family size and seasonality controls}

Following a series of papers in the consumption literature I assume that family size enters the utility function multiplicatively, and thus include $\Delta \ln$ (familiy size) in the log-linearized Euler equations. $\Delta \ln$ (familiy size) is defined as the log average family size in the third and fourth interview minus the $\log$ average family size in the first and second interview. It is, however, not clear that such a simple correction accurately captures family size effects. The literature on equivalence scales considers this issue in detail. Here, I choose to repeat the estimations using households consisting of only a single individual in both periods to see if this affects the results. Single individual households may also face a much simpler optimization problem making it easier to detect the relation between consumption growth and stock and/or T-bill returns in the microdata.

I assume that seasonality also enters as a multiplicative factor in the utility function, such that in the CRRA case, $U\left(C_{m}+C_{m+1}+C_{m+2}+C_{m+3}+C_{m+4}+C_{m+5}\right)$ $=\frac{1}{1-\gamma}\left(\left(C_{m}+C_{m+1}+C_{m+2}+C_{m+3}+C_{m+4}+C_{m+5}\right) S_{m}\right)^{1-\gamma}$, where $C_{m}$ is consumption per adult equivalent of the household in month $m$ and $S_{m}$ is the seasonal factor (thus $S_{m}$ takes on one of 12 different values $\left.S_{1}, \ldots, S_{12}\right)$. Under this assumption seasonal adjustment by dummies is valid in the log-linearized model.

\footnotetext{
${ }^{6} \mathrm{An}$ argument similar to the one outlined in this section in the CRRA utility case can be given for Epstein-Zin utility. In that case the EIS and the coefficient of relative risk aversion can be estimated consistently using standard GMM methods, but the discount factor cannot.

An alternative way to see that measurement error does not prevent consistent estimation of the EIS in either the CRRA or the Epstein-Zin case is to consider the log-linearized Euler equation stated below in which log consumption growth is a left hand side variable and lagged consumption growth rates are not used as instruments.
} 


\subsubsection{Estimation method}

As discussed in the introduction I estimate log-linearized Euler equations using standard estimation techniques. To avoid the complicated semiannual notation, use $t$ to denote six months long periods and refer to the above sections for the precise definitions of semiannual consumption growth rates and family size changes as well as the timing of the asset returns. As earlier I use $h$ to denote a given household.

Since I only have one consumption growth observation per household I use the simple cohort technique, discussed in the above section on measurement error, in which the consumption growth observation for a given period is the cross-sectional average of the consumption growth observations for households of a given type in the sample for that period. Notice that as long as one consumption growth observation is available per household it is still possible to avoid aggregation problems, since one can average $\Delta \ln C_{t+1}^{h}=\ln \left(\frac{C_{t+1}^{h}}{C_{t}^{h}}\right)$ across households as opposed to using the log of the ratio of the household consumption averages. ${ }^{7}$

The log-linearized conditional Euler equations are then, with stockholders' Euler equation for the stock return as an example

$\frac{1}{H_{t}^{s}} \sum_{h=1}^{H_{t}^{s}} \Delta \ln C_{t+1}^{h, s}=\sigma \ln \left(1+R_{s, t}\right)+\delta_{1}^{s} D_{1}+\delta_{2}^{s} D_{2}+\ldots+\delta_{12}^{s} D_{12}+\alpha \frac{1}{H_{t}^{s}} \sum_{h=1}^{H_{t}^{s}} \Delta \ln (\text { family size })_{t+1}^{h, s}+u_{t+1}^{s}$

where $\sigma$ denotes the EIS, $D_{1}, \ldots, D_{12}$ are seasonal dummies, $R_{s}$ denotes the net stock return, and $H_{t}^{s}$ denotes the number of stockholders in the cross-section at date $t$.

This equation is valid under CRRA preferences as well as under Epstein-Zin utility. In the CRRA case, $\delta_{i}^{s}$ is a function of $\beta$ and of the conditional variances and covariances of the log gross stock return and $\log$ consumption growth in the CRRA case. In the Epstein-Zin case $\delta_{i}^{s}$ includes additional terms involving the variance of and conditional covariances with the return on the total portfolio of assets held by the agents. See again Attanasio and Weber (1989) for the derivations of the log-linearized Euler equation in the Epstein-Zin case. The error term $u_{t}$ includes the expectational errors for log consumption growth and log stock returns and the measurement error in log consumption growth. If the conditional variances and covariances in $\delta_{i}^{s}$ are not constant, the stochastic components enter the error term. This does not cause problems for the estimation as long as these components are

\footnotetext{
${ }^{7}$ While theoretically important this distinction turns out not to matter much in the CEX data, most likely due to substantial measurement error in the consumption data. Brav, Constantinides and Geczy (1999) conclude that tests of the representative agent (complete insurance) model against the nonrepresentative agent (incomplete insurance) model have very low power. Their results are based on a Monte Carlo simulation designed to capture the main features of the CEX data set.
} 
uncorrelated with the instruments used.

The estimation method used is linear GMM estimation, or in other words linear instrumental variables estimation modified to account for autocorrelated error terms of the MA(5) form as well as for heteroscedasticity of arbitrary form. Heteroscedasticity is likely to be present because of a varying number of observations per quarter. Instrumental variables estimation is used rather than OLS because of endogeneity of asset returns due to the expectational error being included in the error term. For stockholders (also assumed to be bondholders according to my classification), the Euler equations for the stock and T-bill returns are also estimated jointly, again using linear GMM estimation. Joint estimation is used to gain efficiency from exploiting cross-equation correlation in error terms caused by correlated expectational errors. Furthermore, it makes it possible to impose identical values for $\sigma$ to determine if this leads to rejection of the model according to overidentification tests as Hansen and Singleton (1983) showed to be the case in aggregate US data. In the joint estimation, the coefficients on the seasonal dummies are allowed to differ for the stock and the bond equation since this is implied by the model when the two returns have different variances or different covariances with log consumption growth.

\subsection{Results and discussion}

The results of the instrumental variables estimations of the log-linearized model in equation (10) are shown in Tables 2-4. Each table shows estimates of $\sigma$ for three sets of estimations corresponding to three different sets of instruments. All instrument sets include 12 seasonal dummies and $\Delta \ln$ (family size). In addition instrument set 1 includes the log dividend price ratio. Instrument set 2 includes the log dividend price ratio, the lagged log real stock return and the lagged log real T-bill return. Instrument set 3 includes the log dividend price ratio, the bond horizon premium and the bond default premium. See section 2.2.1 for the precise timing of these variables. The dividend price ratio is well known to be among the best predictors of real stock returns and is also a good predictor of the T-bill return for the time period considered here. As for instrument set 2, many previous studies have used lagged asset returns as instruments. For this time period, the contemporaneous dividend-price ratio and the T-bill returns are highly correlated and results based instrument set 2 are fairly similar if the log dividend-price ratio is excluded. The inclusion of the bond horizon premium and the bond default premium is motivated by the findings of Fama and French (1989) that these have predictive power for stock returns. Leaving out the family size variable, the $R^{2}$ from regressing the log real stock return on the variables in the three instrument sets is $0.117,0.143$, and 0.148 for semiannual data. The corresponding $R^{2}$ values for the $\log$ real T-bill return are $0.673,0.674$, and 0.744 .

While other variables in the information set should also be uncorrelated with the error terms in the log-linearized Euler equations according to economic theory, the properties of the estimators may 
deteriorate if weak instruments are included. It is known that the 2SLS estimator tends to be biased towards the biased and inconsistent OLS estimator. If the explanatory power of the first stage is fixed while more instruments are added, the bias becomes progressively worse (see Anderson and Sawa (1979)). This motivates the use of small sets of instruments. Adding in more instruments tended to push the estimates of the EIS closer to 0 for all groups.

The results of the estimations are favorable to the limited participation theory. The top half of Table 2 shows the estimation results for the Euler equation for the stock return. For instrument set 1, the EIS is estimated to be 0.299 for stockholders. The estimate is significant at the 5 percent level. The separate estimations for the three layers of stockholders, show that the relatively high value of the EIS for stockholders is driven by a higher estimate for the richest layer of stockholders. One interpretation is that wealthier stockholders have a higher elasticity of substitution. Alternatively, it is possible that households with small equity stakes do not satisfy the Euler equation for the stock market index return to a reasonable approximation (e.g. due to transactions costs or poorly diversified equity portfolios). For non-stockholders, the estimate of the EIS is close to zero. A Wald test rejects that the EIS is the same for stockholders and non-stockholders at the 10 percent level. When adding more instruments, using instrument set 2 and 3, the results remain similar.

The estimation results for the Euler equation for the T-bill return are shown in the bottom half of Table 2. They show the same patterns as the results based on the stock return with a positive and significant estimate of the EIS around 0.8 for bondholders and a small, insignificant estimate for non-bondholders. Again, the EIS is estimated to be larger, around 1.6, for the top layer of bondholders.

The coefficients on $\Delta \ln$ (family size) (not shown) further supports the hypothesis that the Euler equations for the stock return and the T-bill return hold for households who own the asset in question, but not for others. For those who hold the asset, the coefficient on $\Delta \ln$ (family size) is typically significantly different from zero with a point estimate around 0.6, while change in log family size has a smaller and insignificant effect in the Euler equations for households who do not hold the asset.

An important negative finding based on the instrumental variables estimations in Table 2 is that there is no tendency for $\chi^{2}$ tests of overidentifying restrictions to reject for non-stockholders and nonbondholders but not for stockholder and bondholders as would be expected. For instrument set 2 the overidentifying restrictions are not rejected for stockholders and are rejected for non-stockholders at the 10 percent level for both asset returns, but the opposite is the case for instrument set 3 . To determine the effects of restricting the EIS to be the same across the Euler equations for stocks and T-bills for a given group of households, Table 3 shows the joint estimation of the two Euler equations for the stockholder non-stockholder distinction. Under my categorizations all stockholders are also categorized as bondholders and the tests of overidentification should reject for non-stockholders but not for stockholders. As the table shows, the tests of overidentifying restrictions are now rejected 
for both stockholders and non-stockholders. The fact that the overidentifying restrictions are now consistently rejected even for stockholders is consistent with the previous results that EIS estimates for stockholders (around 0.3) are lower than EIS estimates for bondholders (around 0.8), despite the fact that most households in these two categories are the same according to my classifications. It may be the case that the much lower power of the instruments for predicting the real stock return lead to substantial small sample bias of the instrumental variables estimator.

In addition to considering different instrument sets, several other robustness check were done. Firstly, the estimations were performed for households consisting of one individual only. The results, included in the tables, show even larger differences between stockholders and non-stockholders and between bondholders and non-bondholders. In my view, this most likely reflect the fact that these households face much simpler optimization problems, making it easier to detect the relation between consumption growth and asset returns. Secondly, I repeated the estimations assuming a representative agent within the set of stockholders and within the set of non-stockholders. The results (not shown) were similar. As mentioned that was to be expected given the simulation results of Brav, Constantinides and Geczy (1999) regarding the possibility to differentiate between the representative agent (complete insurance) model against the nonrepresentative agent (incomplete insurance) using CEX data. Thirdly, I considered estimators that are invariant to whether consumption growth is regressed on asset returns or the other way around. For instrument set 1 this is not an issue since the model is just identified (when estimating one Euler equation at a time) and thus leads to the same estimate of the EIS regardless of whether consumption growth or the interest rate is used as right hand side variable. For instrument set 2 and 3, the continuously updated GMM estimator of Hansen, Heaton, and Yaron (1996) was difficult to make converge and lead to results very sensitive to the exact specification of the model. Instead, a simple LIML estimation (without corrections for heteroscedasticity and autocorrelation) was performed, with results similar to those reported in Table 2 for each of the two Euler equations. Finally, I considered an alternative to taking cross-sectional averages over stockholders and non-stockholders which should be more robust to measurement error in consumption in the case of a relatively small number of households in the cross-section. If the Euler equation for a given asset return holds for each assetholder, one can use the stochastic discount factor based on the consumption of any of the assetholders to estimate it. As an alternative to the time series of cross-sectional averages of log consumption growth rates, I therefore constructed a times series in which the consumption growth rate for a given period for a given group of households was the median consumption growth rate for that period for that group of households. The corresponding time series of observations of $\Delta \ln$ (family size) for this particular set of households was constructed as well. Results corresponding to those in Table 2 are shown in Table 4. The results again confirm the importance of distinguishing between assetholders and non-assetholders. The estimates of the EIS for 
stockholders and for bondholders are larger than before, further supporting the limited participation hypothesis. The Euler equation for the stock return lead to EIS estimates around 0.4 for stockholders (larger for single stockholders), while the Euler equation for the T-bill return result in EIS estimates around 1 for bondholders.

Overall, the limited participation hypothesis is supported by the differences in coefficient estimates across stockholders and non-stockholders and across bondholders and non-bondholders, but not by the tests of overidentifying restrictions. The baseline results are robust to a variety of changes to the specification and estimation method. As discussed earlier, the more important specification choice is the use of semiannual data rather than higher frequency consumption growth rates.

It should be pointed out that my estimations of the EIS are based on pre-tax returns since it is not possible to calculate accurate household-specific tax rates for capital income in the CEX. ${ }^{8}$ It is however possible to get an idea of the bias taxes may introduce in EIS estimates. Suppose the tax rate on the total net return (income return plus capital gains) to asset $i$ is $\tau_{i}$. Then the correct $\log$ return to holding asset $i$ from $t$ to $t+1$ is $\ln \left(1+\left(1-\tau_{i}\right) R_{i t}\right)$, which fluctuates less than $\ln \left(1+R_{i t}\right)$. Thus ignoring taxes leads to a downward biased estimate of the EIS since a smaller value is needed to 'translate' the too large fluctuations in $\ln \left(1+R_{i t}\right)$ into consumption growth changes. Using the approximation $\ln (1+x) \simeq x$ the right hand side variable should be $\ln \left(1+\left(1-\tau_{i}\right) R_{i t}\right) \simeq$ $\left(1-\tau_{i}\right) R_{i t}$ but is $\ln \left(1+R_{i t}\right) \simeq R_{i t}$. Thus I am approximately estimating $\left(1-\tau_{i}\right) \sigma$, not $\sigma$. This further strengthens the case that the EIS is not zero for stockholders and bondholders.

In comparison to the literature it is relevant to discuss EIS estimates for households who hold savings accounts but no stocks, bonds or mutual funds or U.S. savings bonds. The majority of households (around two thirds in the CEX whether weighting households using the CEX weights or not) have positive holdings in savings accounts. Since the return on such assets is fairly highly correlated with the T-bill return one may have expected results based on aggregate consumption to lead to significantly positive estimates of the EIS. In the CEX, estimates of the EIS based on the Tbill return are still small, around 0.15 , for households with savings account holdings who do not hold stocks, bonds, mutual funds or U.S. savings bonds. They are around 0.4 but with a standard error around 0.7 when using the real return on savings accounts, calculated based on a series of passbook savings account returns obtained from the Federal Reserve Board. For both return series, the estimates for this group of households are somewhat sensitive to instrument choice. This is true even for the wealthiest third of households with positive savings but no stocks, bonds or mutual funds or U.S.

\footnotetext{
${ }^{8}$ As discussed earlier, it cannot be determined whether households reporting positive holdings of the category stock, bonds or mutual funds hold both stocks or bonds or only one of these types of assets. When classifying households I assumed they hold both, but without specific information about whether this is correct, as well as dates of purchase, accurate household level tax adjustments are infeasible.
} 
savings bonds. One possibility is that most households with only savings (and typically also checking) account holdings have too little financial wealth for it to be optimal to do sophisticated intertemporal optimization. An other possibility is that households with small savings account holdings (and no stocks etc.) may in reality be net borrowers, or be borrowing constrained, holding just a small amount of assets in a savings account for precautionary purposes. As mentioned in the introduction, the findings of Gross and Souleles (2001) suggest that once a more appropriate interest rate is used for borrowers (in their case the credit card rate), borrowing and thus consumption growth is sensitive to the interest rate suggesting a non-zero EIS.

\section{Conclusion}

The paper suggests that accounting for limited asset market participation is important for estimation of the elasticity of intertemporal substitution. Differences in the estimates of the EIS between assetholders and non-assetholders are large and statistically significant. This is the case whether estimating the EIS based on the Euler equation for the NYSE stock index return and distinguishing between stockholders and non-stockholders as best possible or estimating the EIS based on the Euler equation for T-bills and distinguishing between bondholders and non-bondholders. Estimates of the EIS are around 0.3-0.4 for stockholders and 0.8-1 for bondholders, and are larger for households with larger asset holdings within these two groups.

I do not attempt here to explain why some households chose corner solutions for stocks and/or bonds. I have argued elsewhere (Vissing-Jørgensen (2000)) that information costs work as entry costs and per period market participation costs making it suboptimal for households with low or moderate financial wealth to enter these markets. 


\section{References}

Anderson, T. W., and T. Sawa. "Evaluation of the Distribution Function of the Two-Stage Least Squares Estimate." Econometrica 47 (January 1979): 163-182.

Attanasio, O. P., J. Banks, and S. Tanner. "Asset Holding and Consumption Volatility." Journal of Political Economy, this issue.

Attanasio, O. P., and M. Browning. "Consumption over the Life Cycle and over the Business Cycle." American Economic Review 85 (December 1995): 1118-1137.

Attanasio, O. P., P. K. Goldberg, and E. Kyriazidou. "Credit Constraints in the Market for Consumer Durables: Evidence from Micro Data on Car Loans." NBER Working paper, No. $7694,2000$.

Attanasio, O. P. and G. Weber. "Intertemporal Substitution, Risk Aversion and the Euler Equation for Consumption.", Economic Journal 99 (No. 395, 1989): 59-73.

Attanasio, O. P. and G. Weber. "Consumption Growth, the Interest Rate and Aggregation." Review of Economic Studies 60 (July 1993): 631-649.

Attanasio, O. P. and G. Weber. "Is Consumption Growth Consistent with Intertemporal Optimization? Evidence from the Consumer Expenditure Survey." Journal of Political Economy 103 (December 1995): 1121-1157.

Brav, A. and C. Geczy. "An Empirical Resurrection of the Simple Consumption CAPM with Power Utility." Working paper, University of Chicago, 1996.

Brav, A., G. M. Constantinides, and C. Gezcy. "Asset Pricing with Heterogeneous Consumers and Limited Participation: Empirical Evidence." Working paper, University of Chicago, 1999.

Daniel, K., and D. Marshall. "The Equity Premium Puzzle and the Risk-Free Rate Puzzle at Long Horizons." Macroeconomic Dynamics 1 (No. 2, 1997): 452-484. 
Fama, E. F. and K. R. French. "Business Conditions and Expected Returns on Stocks and Bonds." Journal of Financial Economics 25 (1989): 23-49.

Gabaix, X. and D. Laibson, 2001, "The 6D bias and the Equity Premium Puzzle." Forthcoming in NBER Macroeconomics Annual, 2001.

Gross, D. B., and N. S. Souleles. "Do Liquidity Constraints and Interest Rates Matter for Consumer Behavior? Evidence from Credit Card Data." Forthcoming, Quarterly Journal of Economics, 2001.

Hall, R. E. "Intertemporal Substitution in Consumption." Journal of Political Economy 96 (April 1998): 339-357.

Hansen, L. P., J. Heaton, and A. Yaron. "Finite-Sample Properties of Some Alternative GMM Estimators." Journal of Business and Economic Statistics 14 (July 1996): 262-280.

Hansen, L. P., and K. J. Singleton. "Stochastic Consumption, Risk Aversion, and the Temporal Behavior of Asset Returns." Journal of Political Economy 91 (April 1983): 249-65.

Ibbotson Associates. Stocks, Bonds, Bills, and Inflation 1997 Yearbook. Chicago: Ibbotson Associates, 1997.

Jones, L. E., R. Manuelli, and H. Siu. "Growth and Business Cycles." NBER Working Paper No. 7633, 2000.

Lynch, A. W. "Decision Frequency and Synchronization Across Agents: Implications for Aggregate Consumption and Equity Return." Journal of Finance 51, (September 1996): 14791497.

Mankiw, N.G. and S. Zeldes, 1991, "The Consumption of Stockholders and Nonstockholders," Journal of Financial Economics 29 (March 1991): 97-112.

Parker, J. A. "Spendthrift in America? On two Decades of Decline in the U.S. Savings Rate." NBER Macroeconomics Annual (1999): 317-370. 
Vissing-Jørgensen, A. "Limited Stock Market Participation and the Equity Premium Puzzle." Working paper, University of Chicago, 1999.

Vissing-Jørgensen, A. "Towards an explanation of household portfolio choice heterogeneity: Nonfinancial income and participation cost structures." Working paper, University of Chicago, 2000.

Zeldes, S. P. "Consumption and Liquidity Constraints: An Empirical Investigation." Journal of Political Economy, 97 (April 1989): 305-346. 
Table 1: Summary statistics, CEX data, 1982-1996

\begin{tabular}{|c|c|c|c|c|}
\hline Data & Group & $\begin{array}{l}\text { Mean number } \\
\text { of observations } \\
\text { per month }\end{array}$ & $\begin{array}{c}\text { Mean of } \\
\Sigma_{h=1}^{H_{t}} \Delta \ln C_{t+1}^{h} \\
\text { over the sample }\end{array}$ & $\begin{array}{c}\text { Standard deviation } \\
\text { of } \Sigma_{h=1}^{H_{t}} \Delta \ln C_{t+1}^{h} \\
\text { over the sample }\end{array}$ \\
\hline \multirow{11}{*}{$\begin{array}{l}\text { Semiannual, } \\
\text { all household sizes }\end{array}$} & All & 217 & 0.002 & 0.024 \\
\hline & Stockholders & 47 & 0.014 & 0.041 \\
\hline & Non-stockholders & 170 & -0.001 & 0.028 \\
\hline & Bottom stockholder layer & 11 & 0.022 & 0.088 \\
\hline & Middle stockholder layer & 11 & 0.002 & 0.101 \\
\hline & Top stockholder layer & 11 & 0.014 & 0.102 \\
\hline & Bondholders & 68 & 0.010 & 0.034 \\
\hline & Non-bondholders & 148 & -0.001 & 0.030 \\
\hline & Bottom bondholder layer & 17 & 0.005 & 0.069 \\
\hline & Middle bondholder layer & 17 & 0.012 & 0.072 \\
\hline & Top bondholder layer & 17 & 0.008 & 0.073 \\
\hline \multirow{5}{*}{$\begin{array}{l}\text { Semiannual, } \\
\text { single individual } \\
\text { households }\end{array}$} & All & 51 & -0.001 & 0.045 \\
\hline & Stockholders & 10 & 0.009 & 0.098 \\
\hline & Nonstockholders & 41 & -0.003 & 0.052 \\
\hline & Bondholders & 13 & 0.002 & 0.085 \\
\hline & Non-bondholders & 39 & -0.002 & 0.054 \\
\hline
\end{tabular}

Note: $\Sigma_{h=1}^{H_{t}} \Delta \ln C_{t+1}$ is seasonally adjusted using seasonal dummies. The seasonally adjusted value is the sample mean of the series plus the residual from a regression on 12 dummies. 
Table 2: GMM estimation of log linearized Euler equations. Real T-bill return and real value weighted NYSE return, separate estimations. CEX, 1982-1996. Semiannual data.

\begin{tabular}{|c|c|c|c|c|c|c|c|c|}
\hline & \multicolumn{2}{|c|}{ Instrument set 1} & \multicolumn{3}{|c|}{ Instrument set 2} & \multicolumn{3}{|c|}{ Instrument set 3} \\
\hline & $\widehat{\sigma}$ & Std. & $\widehat{\sigma}$ & Std. & $\begin{array}{c}\text { OID test, } \\
\mathrm{df}=2, \mathrm{p} \text {-value }\end{array}$ & $\widehat{\sigma}$ & Std. & $\begin{array}{c}\text { OID test, } \\
\mathrm{df}=2, \mathrm{p} \text {-value }\end{array}$ \\
\hline \multicolumn{9}{|l|}{ Euler equation for stocks } \\
\hline \multicolumn{9}{|l|}{ All household sizes } \\
\hline All & 0.098 & $(0.072)$ & 0.066 & $(0.062)$ & 0.086 & 0.068 & $(0.059)$ & 0.314 \\
\hline Stockholders & 0.299 & $(0.146)$ & 0.281 & $(0.114)$ & 0.260 & 0.200 & $(0.091)$ & 0.018 \\
\hline Non-stockholders & 0.057 & $(0.079)$ & 0.017 & $(0.070)$ & 0.048 & 0.049 & $(0.070)$ & 0.568 \\
\hline Bottom layer & 0.046 & $(0.186)$ & -0.054 & $(0.163)$ & 0.570 & 0.052 & $(0.158)$ & 0.828 \\
\hline Middle layer & 0.175 & $(0.274)$ & 0.350 & $(0.207)$ & 0.547 & 0.173 & $(0.261)$ & 0.027 \\
\hline Top layer & 0.486 & $(0.325)$ & 0.417 & $(0.235)$ & 0.203 & 0.292 & $(0.188)$ & 0.027 \\
\hline Wald test for equal $\sigma$ & $\mathrm{W}$ & p-value & & $\mathrm{W}$ & p-value & & $\mathrm{W}$ & p-value \\
\hline Non-stockholders vs. stockholders & 3.255 & 0.071 & & 4.340 & 0.037 & & 3.296 & 0.069 \\
\hline Non-stockholders vs. top layer & 2.146 & 0.143 & & 2.378 & 0.123 & & 2.941 & 0.086 \\
\hline \multicolumn{9}{|l|}{ Single individual households } \\
\hline All & 0.202 & $(0.172)$ & -0.008 & $(0.106)$ & 0.025 & 0.261 & $(0.139)$ & 0.439 \\
\hline Stockholders & 0.698 & $(0.496)$ & 0.323 & $(0.264)$ & 0.005 & 0.681 & $(0.326)$ & 0.969 \\
\hline Non-stockholders & 0.077 & $(0.143)$ & -0.115 & $(0.137)$ & 0.071 & 0.160 & $(0.123)$ & 0.250 \\
\hline Wald test for equal $\sigma$ & W & p-value & & $\mathrm{W}$ & p-value & & $\mathrm{W}$ & p-value \\
\hline Non-stockholders vs. stockholders & 1.733 & 0.188 & & 1.958 & 0.162 & & 3.866 & 0.049 \\
\hline
\end{tabular}

\section{Euler equation for T-bill}

All household sizes

\begin{tabular}{|c|c|c|c|c|c|c|c|}
\hline All & 0.372 & $(0.232)$ & 0.362 & $(0.225)$ & 0.097 & $0.264 \quad(0.220)$ & 0.143 \\
\hline Bondholders & 0.932 & $(0.368)$ & 0.839 & $(0.360)$ & 0.215 & $0.783(0.353)$ & 0.147 \\
\hline Non-bondholders & 0.105 & $(0.270)$ & 0.087 & $(0.257)$ & 0.024 & $0.005(0.244)$ & 0.382 \\
\hline Bottom layer & 0.986 & $(0.662)$ & 0.798 & $(0.612)$ & 0.492 & $0.726(0.580)$ & 0.244 \\
\hline Middle layer & 0.287 & $(0.550)$ & 0.336 & $(0.544)$ & 0.476 & $0.277 \quad(0.523)$ & 0.627 \\
\hline Top layer & 1.648 & $(0.515)$ & 1.672 & $(0.505)$ & 0.356 & $1.530(0.505)$ & 0.067 \\
\hline Wald test for equal $\sigma$ & $\mathrm{W}$ & $\mathrm{p}$-value & & $\mathrm{W}$ & $\mathrm{p}$-value & W & $\mathrm{p}$-value \\
\hline Non-bondholders vs. bondholders & 4.029 & 0.045 & & 3.192 & 0.074 & 4.127 & 0.042 \\
\hline Non-bondholders vs. top layer & 8.055 & 0.005 & & 8.905 & 0.003 & 7.871 & 0.005 \\
\hline \multicolumn{8}{|l|}{ Single individual households } \\
\hline All & 0.681 & $(0.456)$ & 0.524 & $(0.450)$ & 0.032 & $0.282(0.411)$ & 0.053 \\
\hline Bondholders & 2.624 & $(0.885)$ & 2.759 & $(0.880)$ & 0.163 & $1.617(0.824)$ & 0.007 \\
\hline Non-bondholders & 0.048 & $(0.479)$ & -0.028 & $(0.475)$ & 0.039 & $-0.105(0.460)$ & 0.103 \\
\hline Wald test for equal $\sigma$ & $\mathrm{W}$ & $\mathrm{p}$-value & & W & $\mathrm{p}$-value & W & $\mathrm{p}$-value \\
\hline Non-bondholders vs. bondholders & 8.371 & 0.004 & & 7.527 & 0.006 & 4.722 & 0.030 \\
\hline \multicolumn{8}{|c|}{$\begin{array}{l}\text { Note: } 12 \text { monthly dummies included as explanatory variables and instruments. The estimations for all household sizes } \\
\text { furthermore include } \Delta \ln (\text { family size) as explanatory variable and instrument. In addition the instrument sets include } \\
\text { the following variables. Instrument set } 1: \log \text { dividend price ratio. Instrument set } 2: \log \text { dividend price ratio, lagged } \\
\text { log real value weighted NYSE return, lagged log real T-bill return. Instrument set 3: Log dividend price ratio, default } \\
\text { premium, bond horizon premium. }\end{array}$} \\
\hline
\end{tabular}


Table 3: GMM estimation of log linearized Euler equations. Real T-bill return and real value weighted NYSE return, joint estimations. CEX, 1982-1996. Semiannual data.

\begin{tabular}{|c|c|c|c|c|c|c|c|c|c|}
\hline & \multicolumn{3}{|c|}{ Instrument set 1} & \multicolumn{3}{|c|}{ Instrument set 2} & \multicolumn{3}{|c|}{ Instrument set 3} \\
\hline & $\widehat{\sigma}$ & Std. & $\begin{array}{l}\text { OID test, } \\
\quad \mathrm{df}=1 \\
\text { p-value }\end{array}$ & $\widehat{\sigma}$ & Std. & $\begin{array}{l}\text { OID test, } \\
\qquad \mathrm{df}=5, \\
\text { p-value }\end{array}$ & $\widehat{\sigma}$ & Std. & $\begin{array}{l}\text { OID test, } \\
\qquad \mathrm{df}=5, \\
\text { p-value }\end{array}$ \\
\hline \multicolumn{10}{|l|}{ All household sizes } \\
\hline All & 0.080 & $(0.077)$ & 0.025 & 0.046 & $(0.058)$ & 0.036 & 0.026 & $(0.045)$ & 0.016 \\
\hline Stockholders & 0.442 & $(0.144)$ & 0.022 & 0.404 & $(0.114)$ & 0.071 & 0.261 & $(0.079)$ & 0.011 \\
\hline Non-stockholders & 0.013 & $(0.057)$ & 0.036 & 0.003 & $(0.022)$ & 0.041 & 0.003 & $(0.033)$ & 0.028 \\
\hline Bottom layer & 0.006 & $(0.054)$ & 0.141 & 0.003 & $(0.021)$ & 0.372 & 0.007 & $(0.026)$ & 0.078 \\
\hline Middle layer & 0.068 & $(0.173)$ & 0.175 & 0.242 & $(0.203)$ & 0.218 & 0.048 & $(0.040)$ & 0.041 \\
\hline Top layer & 0.700 & $(0.354)$ & 0.020 & 0.422 & $(0.260)$ & 0.190 & 0.324 & $(0.179)$ & 0.004 \\
\hline Wald test for equal $\sigma$ & W & $\mathrm{p}$-value & & W & $\mathrm{p}$-value & & W & $\mathrm{p}$-value & \\
\hline $\begin{array}{l}\text { Non-stockholders vs. } \\
\text { stockholders }\end{array}$ & 9.228 & 0.002 & & 12.886 & 0.0003 & & 13.677 & 0.0002 & \\
\hline $\begin{array}{l}\text { Non-stockholders vs. } \\
\text { top layer of stockholders }\end{array}$ & 3.890 & 0.049 & & 2.127 & 0.145 & & 4.211 & 0.040 & \\
\hline \multicolumn{10}{|l|}{ Single individual households } \\
\hline All & 0.187 & $(0.192)$ & 0.055 & 0.024 & $(0.041)$ & 0.036 & 0.141 & $(0.120)$ & 0.062 \\
\hline Stockholders & 1.108 & $(0.527)$ & 0.028 & 0.378 & $(0.306)$ & 0.023 & 0.568 & $(0.278)$ & 0.043 \\
\hline Non-stockholders & 0.018 & $(0.089)$ & 0.114 & -0.028 & $(0.050)$ & 0.068 & 0.050 & $(0.074)$ & 0.079 \\
\hline Wald test for equal $\sigma$ & $\mathrm{W}$ & $\mathrm{p}$-value & & W & $\mathrm{p}$-value & & W & p-value & \\
\hline $\begin{array}{c}\text { Non-stockholders vs. } \\
\text { stockholders }\end{array}$ & $4.161^{*}$ & 0.041 & & $1.716^{*}$ & 0.190 & & $3.250^{*}$ & 0.071 & \\
\hline $\begin{array}{l}\text { Note: } 12 \text { monthly dummies ir } \\
\text { furthermore include } \Delta \ln \text { (fam } \\
\text { the following variables. Instr } \\
\text { log real value weighted NYSE } \\
\text { premium, bond horizon premi } \\
\text { across the Euler equations for } \\
\text { definite. }\end{array}$ & $\begin{array}{l}\text { lded as } \\
\text { size) as } \\
\text { ent set } 1 \\
\text { turn, las } \\
\text { The } \mathrm{T} \\
\text { ck sand }\end{array}$ & $\begin{array}{l}\text { explanatc } \\
\text { explanat } \\
\text { : Log di } \\
\text { gged log } \\
\text { Vald test } \\
\text { T-bills. }\end{array}$ & $\begin{array}{l}\text { ory variable } \\
\text { tory variabl } \\
\text { vidend pric } \\
\text { real T-bill } \\
\text { s denoted b } \\
\text { Allowing fo }\end{array}$ & $\begin{array}{l}\text { le and } i \\
\text { ce ratio. } \\
\text { return. }\end{array}$ & $\begin{array}{l}\text { Instrur } \\
\text { Instrum } \\
\text { terics do }\end{array}$ & $\begin{array}{l}\text { nts. The } \\
\text { nt. In add } \\
\text { ment set } 2 \text { : } \\
\text { nent set } 3 \text { : } \\
\text { not allow }\end{array}$ & $\begin{array}{l}\log d i \\
\log d i\end{array}$ & $\begin{array}{l}\text { vidend } \\
\text { vidend } \\
\text { relation } \\
\text { nvolved }\end{array}$ & $\begin{array}{l}\text { ousehold } \\
\text { it sets inc } \\
\text { ratio, la } \\
\text { ratio, de } \\
\text { he error te } \\
\text { being pos }\end{array}$ \\
\hline
\end{tabular}


Table 4: GMM estimation of log linearized Euler equations. Real T-bill return and real value weighted NYSE return, separate estimations. CEX, 1982-1996. Semiannual data. Median household approach.

\begin{tabular}{|c|c|c|c|c|c|c|c|c|}
\hline & \multicolumn{2}{|c|}{ Instrument set 1} & \multicolumn{3}{|c|}{ Instrument set 2} & \multicolumn{3}{|c|}{ Instrument set 3} \\
\hline & $\widehat{\sigma}$ & Std. & $\widehat{\sigma}$ & Std. & $\begin{array}{c}\text { OID test, } \\
\mathrm{df}=2, \mathrm{p} \text {-value }\end{array}$ & $\widehat{\sigma}$ & Std. & $\begin{array}{c}\text { OID test, } \\
\mathrm{df}=2, \mathrm{p} \text {-value }\end{array}$ \\
\hline \multicolumn{9}{|l|}{ Euler equation for stocks } \\
\hline \multicolumn{9}{|l|}{ All household sizes } \\
\hline All & 0.125 & $(0.081)$ & 0.069 & $\overline{(0.067)}$ & 0.016 & 0.138 & $(0.064)$ & 0.691 \\
\hline Stockholders & 0.437 & $(0.229)$ & 0.451 & $(0.175)$ & 0.147 & 0.287 & $(0.105)$ & 0.014 \\
\hline Non-stockholders & 0.055 & $(0.081)$ & -0.014 & $(0.073)$ & 0.073 & 0.113 & $(0.074)$ & 0.352 \\
\hline Bottom layer & 0.054 & $(0.231)$ & 0.082 & $(0.191)$ & 0.320 & -0.016 & $(0.201)$ & 0.408 \\
\hline Middle layer & -0.082 & $(0.340)$ & 0.067 & $(0.233)$ & 0.097 & 0.228 & $(0.278)$ & 0.006 \\
\hline Top layer & 1.072 & $(0.798)$ & 0.933 & $(0.538)$ & 0.019 & 0.706 & $(0.367)$ & 0.886 \\
\hline Wald test for equal $\sigma$ & W & p-value & & W & p-value & & $\mathrm{W}$ & p-value \\
\hline Non-stockholders vs. stockholders & 2.833 & 0.092 & & 4.900 & 0.027 & & 4.203 & 0.040 \\
\hline Non-stockholders vs. top layer & 1.687 & 0.194 & & 2.331 & 0.127 & & 4.116 & 0.042 \\
\hline \multicolumn{9}{|l|}{ Single individual households } \\
\hline All & 0.348 & $(0.257)$ & 0.168 & $(0.145)$ & 0.028 & 0.347 & $(0.182)$ & 0.877 \\
\hline Stockholders & 1.152 & $(0.897)$ & 1.030 & $(0.622)$ & 0.090 & 0.874 & $(0.479)$ & 0.661 \\
\hline Non-stockholders & 0.238 & $(0.206)$ & 0.044 & $(0.127)$ & 0.058 & 0.268 & $(0.153)$ & 0.624 \\
\hline Wald test for equal $\sigma$ & $\mathrm{W}$ & p-value & & $\mathrm{W}$ & p-value & & W & p-value \\
\hline Non-stockholders vs. stockholders & 1.350 & 0.245 & & 3.853 & 0.050 & & 3.438 & 0.064 \\
\hline
\end{tabular}

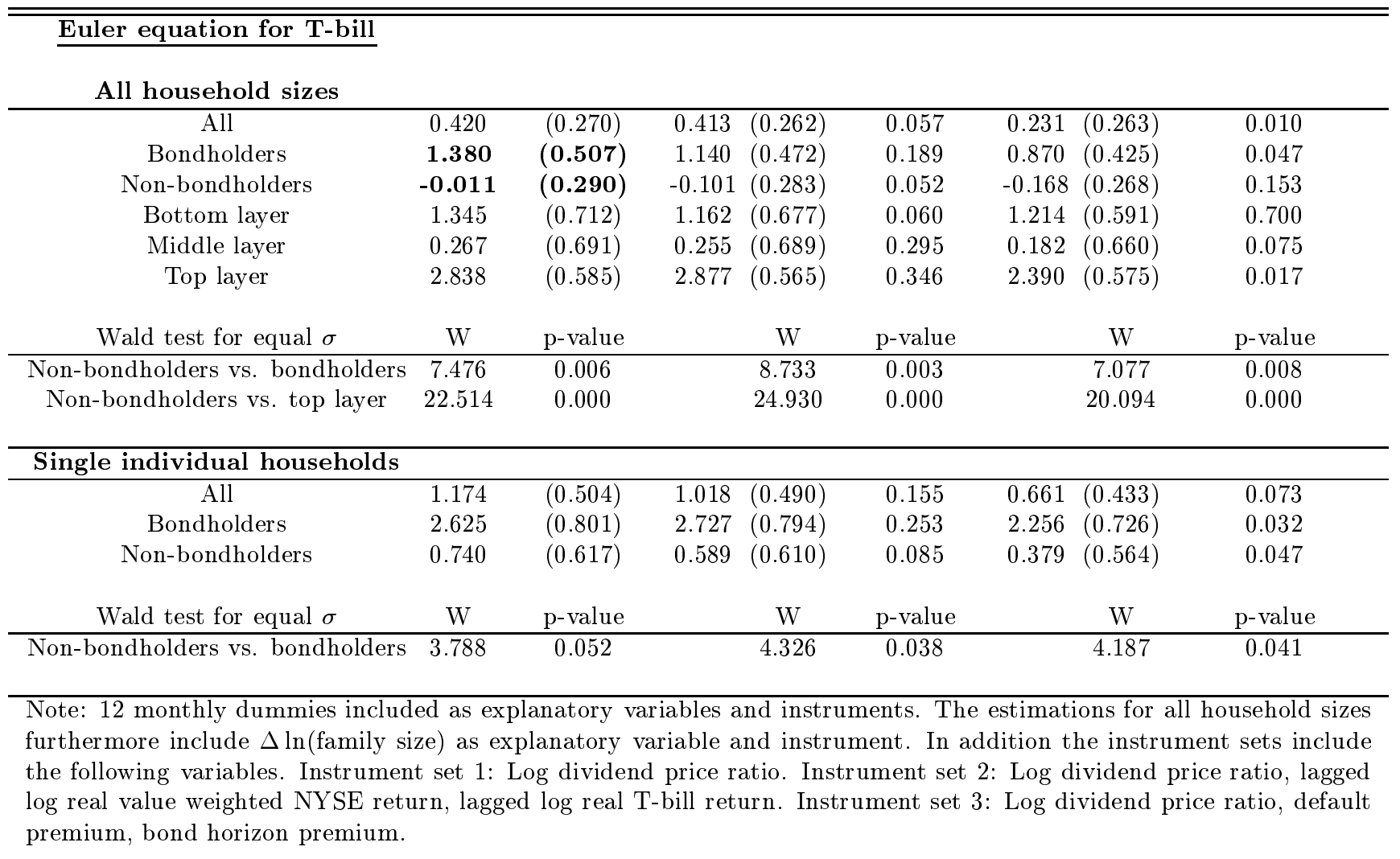

